\title{
KARAKTERISTIK BAHASA PEDAGANG KAKI LIMA PASAR PAGI KOTA SABANG
}

\author{
Wirduna $^{1}$, Rahmad Nuthihar ${ }^{2}$, Sri Widya ${ }^{3}$ \\ Program Studi Pendidikan Bahasa dan Sastra Indonesia \\ Fakultas Keguruan dan Ilmu Pendidikan, Universitas Abulyatama ${ }^{1}$ \\ Dosen Bahasa Indonesia pada Program Studi Instalasi dan \\ Pemeliharaan Jaringan Listrik, Akademi Komunitas Negeri Aceh Barat ${ }^{2}$ \\ Program Studi Pendidikan Bahasa dan Sastra Indonesia \\ Fakultas Keguruan dan Ilmu Pendidikan, Universitas Abulyatama ${ }^{3}$ \\ Surel: wirduna_fkip@abulyatama.ac.id ${ }^{1}$,rahmad.nuthihar@aknacehbarat.ac.id ${ }^{2}$ \\ sriwidyaa06@gmail.com ${ }^{3}$
}

\begin{abstract}
Abstrak
Penelitian ini bertujuan mendeskripsikan jenis karakteristik tindak tutur pedagang kaki lima pasar pagi Kota Sabang. Kota Sabang merupakan kota wisata yang banyak dikunjungi oleh wisatawan lokal dan mancanegara. Adanya keberagaman tersebut diyakini menimbulkan karakteristik tersendiri terkait penggunaan bahasa oleh pedagang dalam transaksi jual beli. Penelitian ini menggunakan pendekatan kualitatif dan termasuk jenis penelitian deskriptif. Pengumpulan data dilakukan dengan teknik rekam, simak, dan catat. Data diolah dengan langkah mengidentifikasi data, mengklasifikasi data, dan menganalisis data. Hasil penelitian ini menunjukkan adanya karakteristik strategi yang digunakan oleh pedagang dalam interaksi jual beli yang berbeda-beda. Jenis karakteristik strategi tindak tutur yang digunakan pedagang kaki lima pasar pagi Kota Sabang meliputi: dua jenis strategi penghormatan, tiga strategi keengganan, empat strategi penghindaran, sepuluh strategi perayuan, dan dua strategi penghargaan. Kelima strategi tersebut dipakai dalam transaksi jual beli yang ada pada pedagang kaki lima pasar pagi Kota Sabang.
\end{abstract}

Kata Kunci: karakteristik bahasa, strategi tindak tutur, Kota Sabang

\section{JurncAbstract}

Pendidikan Bahasa, Sastra

This study aims to describe the types of speech acts of street vendors in the morning market of Sabang City. Sabang City is a tourist city that is visited by many local and foreign tourists. The existence of such diversity is believed to cause its own characteristics related to the use of language by traders in buying and selling transactions. This research uses a qualitative approach and includes a type of descriptive research. Data collection is done by recording, listening, and note taking techniques. Data is processed by identifying data, classifying data, and analyzing data. The results of this study indicate the characteristics of the strategies used by traders in different buying and selling interactions. The types of speech act strategies used by the Sabang City morning market street vendors include: two types of respect strategies, three aversion strategies, four avoidance strategies, ten timbering 
strategies, and two reward strategies. The five strategies are used in the sale and purchase transactions that exist in the morning market street vendors at Sabang City

Keywords: language characteristics, speech act strategies, Sabang City

\section{PENDAHULUAN}

Penelitian ini berkenaan dengan karakteristik bahasa pedagang kaki lima Pasar Pagi di Kota Sabang. Penelitian ini penting dilaksanakan untuk mengetahui karakteristik penggunaan bahasa dalam masyarakat. Hal ini sebagaimana pendapat Sumarsono \& Partana (2002:18) yang mengemukakan bahwa bahasa adalah sistem lambang berupa bunyi yang bersifat arbitrer yang dipakai oleh anggota-anggota masyarakat untuk saling berhubungan dan berinteraksi.

Ditinjau berdasarkan cara berkomunikasi, ragam bahasa terbagi atas ragam tulis dan ragam lisan. Pada dasarnya, ragam bahasa dibelah menjadi golongan penutur dan ragam bahasa menurut jenis pemakaian bahasanya (Mulyati, dkk., 2019:1.2). Sementara itu, menurut Putrayasa (2018:10) bahasa dilihat dari topik pembicaraan terdiri atas: (1) ragam sosial; (2) ragam fungsional; (3) ragam jurnalistik; (4) ragam sastra; dan (5) ragam politik serta hukum.

Ragam bahasa dalam transaksi jual beli akan berbeda dengan komunikasi biasa karena sistem perdagangan tradisional tidak mengindahkan $\mid$ aturan perdagangan pada umumnya namun lebih memedulikan bagaimana terjadinya transaksi (Muzdalifah, Sukidin, \& Suharso, 2019).

Komunikasi yang baik antara pedagang dan pembeli haruslah menerapkan umpan balik berupa verbal maupun nonverbal (Rohim, (2009:16). Hal ini diperkuat dengan pendapat Scrhramm (dalam Mulyana (2015:151) komunikasi dianggap sebagai interaksi kedua pihak yang menyandi, menafsirkan, menyandi-balik, mentransmisikan, dan menerima sinyal untuk berbagi informasi. Oleh karena itu, inti dari sebuah komunikasi yang baik haruslah terjadi pertukaran informasi serta menerapkan prinsip kesantunan dan kerja sama.

Bahasa mempunyai aturan-aturan yang saling bergantung dan mengandung struktur yang bisa dianalisis secara terpisah-pisah, karena merupakan suatu sistem (Fajrik, Sofyan, \& Setyari, 2018). Pedagang juga mempunyai bahasa yang memiliki ciri khas tersendiri seperti penggunaan kata-kata sesuai dengan barang yang dijual, kalimat yang digunakan tidak lengkap dan tidak formal, penggunaan bahasa yang dipakai dari berbagai daerah (Sakdiah, Cahyani, \& Nuthihar, 2019).

Penelitian ini akan dilaksanakan di Kota Sabang. Jika dilihat dari segi geografis, Kota Sabang adalah tempat kapal-kapal mancanegara bersinggah, sehingga Kota Sabang dinamakan pelabuhan bebas. Di Pasar Pagi, semua alat dan bahan yang diperlukan ada, mulaicdari peralatan rumah tangga, obatobatan, pakaian, sampai jajanan dan oleh-oleh khas Sabang yang dapat kita temukan. Pasar pagi dibuka dengan waktu yang cukup singkat, biasanya para pedagang mempersiapkan barang dagangan mereka mulai dari pukul 06.00 WIB sampai pukul 12.00 WIB, terkecuali pada hari Jumat dan hari-hari libur besar lainnya. 
Penelitian mengenai karakteristik bahasa pada pedagang sebelumnya pernah dilakukan oleh Fujiastuti (2014:34) menyimpulkan bahwa karakteristik ragam bahasa transaksi jual beli di Pasar Niten Bantul ada tiga. Pertama, penggunaan kata-kata sesuai dengan barang yang dijual. Kedua, kalimat yang digunakan pendek dan tidak lengkap (kalimat tidak formal). Ketiga, penggunaan kata dari bahasa Jawa. Faktor-faktor yang menyebabkan terjadinya karakteristik bahasa pada transaksi jual beli di Pasar Niten Bantul meliputi: (1) faktor usia; (2) faktor pendidikan; dan (3) faktor asal daerah. Fungsi ragam bahasa pada transaksi jual beli di Pasar Niten Bantul meliputi: (1) fungsi emotif; (2) fungsi direktif; (3) fungsi fatik; dan (4) fungsi referensial.

Hasil penelitian Priastuti (2010:5) menyimpulkan karakteristik diksi yang muncul dalam bahasa iklan komersial di radio meliputi: (1) pemakaian kata-kata gaul; (2) pemakaian kata-kata asing; (3) pemakaian kata bersinonim; (4) pemakaian kata khusus; (5) pemakaian kata-kata daerah; dan (6) pemakaian kata bermakna konotasi. Pemakaian kata-kata tersebut didasarkan pada jenis produk yang diiklankan, daerah asal pendengar, usia pendengar, dan keinginan pengiklanan untuk menyampaikan pesan atau informasi iklannya dengan bahasa yang komunikatif, terkesan modern dan gaul, serta mudah dimengerti pendengar.

Pemakaian lima karakteristik diksi tersebut dikarenakan diksi-diksi di atas mampu menampilkan bahasa iklan komersial yang mudah dipahami pendengar, cocok dengan jenis produk iklannya, dan mampu menyampaikan pesan iklan tepat sasaran dan tujuan.
Selanjutnya, Kusumawati (2014:14) menyimpulkan beberapa hal pertama, terdapat enam karakteristik penggunaan bahasa yang ditemukan pada transaksi jual beli di toko online. Karakteristik tersebut meliputi: (1) alih kode dan campur kode; (2) pelepasan afiks; (3) interferensi morfologi; (4) bentuk kependekan yang meliputi singkatan, akronim, serta penggalan; (5) penggunaan huruf, angka, dan tanda, serta (6) penggantian tulisan.

Kedua, terdapat tiga bentuk istilahistilah khusus pada penggunaan bahasa jual beli online yang meliputi: (1) penggunaan istilah khusus dalam bidang jual beli online; (2) penggunaan istilahistilah dalam media online yang digunakan sebagai sarana komunikasi jual beli online; dan (3) bentuk sapaan khusus. Ketiga, ada dua faktor sosial yang membedakan kelas sosial para pelaku transaksi jual beli online sehingga mempengaruhi penggunaan bahasa yang digunakan, yakni tingkat pendidikan dan tingkat ekonomi. Penggunaan bahasa pada pedagang akan berbeda dengan penyandang afasia broca bahasa karena mereka tidak dapat menggunakan medium bahasa sebagaimana fungsinya (Nasrullah, Suganda, Wagiati, \& Riyanto, 2019).

Berdasarkan uraian di atas mengenai karakteristik bahasa pedagang kaki lima Pasar Pagi Kota Sabang, peneliti tertarik melakukan penelitian ini karena pedagang menggunakan tuturan yang berkarakter dan mempunyai ciri khas tersendiri untuk menarik respons pembeli agar membeli dagangannya. Oleh karena itu, peneliti akan mengkaji bagaimana karakteristik bahasa yang digunakan dalam transaksi jual beli yang 
terdapat pada pedagang kaki lima Pasar Pagi Kota Sabang.

\section{METODE}

Penelitian ini dilakukan di Pasar Pagi Kota Sabang. Pasar Pagi dijadikan sebagai tempat penelitian karena berada di pusat kota dan memenuhi semua kebutuhan masyarakat sehingga peneliti lebih mudah mendapatkan data. Jenis dan pendekatan penelitian yang digunakan dalam penelitian ini adalah metode kualitatif dengan pendekatan deskriptif kualitatif.

Metode ini digunakan untuk memecahkan masalah aktual dengan cara mengumpulkan data, menyusun, mengklasifikasikan, meng-analisis, serta menginterpretasikannya (Narbuko \& Achmadi, 2002:44). Pendekatan kualitatif dipakai untuk memahami fenomena yang dialami oleh subjek penelitian, misalnya: motivasi, perilaku, tindakan, dan persepsi.

Sumber data dalam penelitian ini adalah pedagang kaki lima pasar pagi Kota Sabang yang sedang menjalankan transaksi jual beli. Data dalam penelitian ini berupa karakteristik strategi tindak tutur yang dipakai atau dihasilkan oleh pedagang kaki lima saat menawarkan barang dagangannya. Penelitian ini memerlukan 2 orang pedaganguyang bertindak sebagai responden. Adapun syarat-syarat untuk menjadi responden di antaranya: (1) laki-laki/perempuan; (2) berakal sehat; dan (3) mampu berbicara dengan baik.

Teknik pengumpulan data dilakukan dengan teknik rekam, teknik simak, dan Teknik catat. Tujuan dari teknik rekam adalah untuk mencari data berupa katakata yang dipakai atau dihasilkan oleh pedagang kaki lima. Teknik simak dalam hal ini dilakukan dengan mendengar percakapan yang secara langsung dari alat perekam untuk memperoleh data mengenai karakteristik bahasa pedagang kaki lima yang muncul. Kemudian setelah melakukan penyimakan dan ditentukan objek yang akan diteliti, kemudian dilakukan pencatatan sehingga data yang semula berwujud lisan menjadi data yang berwujud tertulis. Pencatatan dilakukan langsung setelah penyimakan dilakukan.

Analisis data dilakukan dengan tahapan identifikasi data, klasifikasi data, dan data yang sudah dianalisis selanjutnya direkap dalam lembar rekam data, sehingga dapat diketahui jenis pemakaian yang digunakan dalam transaksi jual beli (Yahya, 2013:32).

\section{HASIL DAN PEMBAHASAN}

Hasil penelitian ini menunjukkan adanya strategi yang digunakan oleh pedagang yang berbeda-beda di antaranya strategi penghormatan, strategi keengganan, strategi penghindaran, strategi perayuan, dan strategi penghargaan. Dalam penelitian ini ditemukan lima strategi karakteristik. Jenis strategi perayuan paling banyak ditemukan. Strategi selanjutnya yaitu penghindaran, strategi keengganan, strategi penghormatan, dan strategi penghargaan. Strategi tindak tutur yang ditemukan dalam penelitian ini meliputi sepuluh strategi perayuan, empat strategi penghindaran, tiga strategi keengganan, dua strategi penghormatan, dan dua strategi penghargaan.

Hasil penelitian menunjukkan bahwa dalam transaksi jual beli pedagang pasar pagi Kota Sabang ditemukan lima strategi tindak tutur. Berikut ini hasil analisis data dan pembahasan penelitian. 
Tabel 1

Analisis Jenis Karakteristik Strategi Tindak Tutur

\begin{tabular}{|c|l|l|}
\hline No. & \multicolumn{1}{|c|}{ Jenis Strategi Tindak Tutur } & \multicolumn{1}{c|}{ Jumlah Tindak Tutur } \\
\hline 1. & Strategi Perayuan & 10 tindak Tutur \\
\hline 2. & Strategi Penghindaran & 4 Tindak Tutur \\
\hline 3. & Strategi Keengganan & 3 Tindak Tutur \\
\hline 4. & Strategi Penghormatan & 2 Tindak Tutur \\
\hline 5. & Strategi Penghargaan & 2 Tindak Tutur \\
\hline & Total & 21 Tindak Tutur \\
\hline
\end{tabular}

Kelima karakteristik strategi tindak tutur tersebut dianalisis berdasarkan korpus data yang telah diklasifikasikan dari kumpulan tindak tutur pedagang kaki lima pasar pagi Kota Sabang. Adapun korpus data penelitian ini adalah sebagai berikut.

Tabel 2

Korpus Data Karakteristik Strategi Tindak Tutur Pedagang Kaki Lima Pasar Pagi Kota Sabang

\begin{tabular}{|c|c|c|}
\hline No . & Data & $\begin{array}{c}\text { Jenis Strategi Tindak } \\
\text { Tutur }\end{array}$ \\
\hline 1. & $\begin{array}{l}\text { PB: Aer mawar satu, Kak! } \\
\text { PJ: Satu aja Dek oy? ambel dua kakak kasi } \\
\quad \text { kurang lagi, ambel tros dua } e !\end{array}$ & Strategi Perayuan \\
\hline 2. & $\begin{array}{l}\text { PJ: Mamper Dek, mamper Bu, masoklah sini } \\
\text { dulu, di liat dulu sini-sini masok aja dulu } \\
\text { yok, murah-murah baju ni kakak kasi } \\
\text { untuk adek aja! } \\
\text { PB: Berapaan yang ini ?urnal llmiah } \\
\text { PJ: Murah aja untuk adek gak mahal-mahasp, s } \\
\text { kakak kasi } 120 \text { aja biasa kakak jual sama } \\
\text { orang } 130 !\end{array}$ & $\begin{array}{l}\text { Strategi Perayuan } \\
\text { astra }\end{array}$ \\
\hline 3. & $\begin{array}{l}\text { PJ: Cantek kali gelangnya ni lah kalok adek } \\
\text { pakek! } \\
\text { PB: Berapa Kak? } \\
\text { PJ: } 45 \text { aja sayangku, coba dulu aja pasti } \\
\text { cantek kali ditangan adek, karna } \\
\text { orangnya putih pasti idop kali dia kalok } \\
\text { dipakek. }\end{array}$ & Strategi Perayuan \\
\hline 4. & PJ: Tiga 100, tiga 100, tiga $100 !$ & Strategi Perayuan \\
\hline
\end{tabular}




\begin{tabular}{|c|c|c|}
\hline & $\begin{array}{l}\text { PB: Warna coklat tu lah Kak! } \\
\text { PJ: ini dekku, cantek kali ni motifnya tinggal } \\
\text { satu lagi, cocok kali dimukak adek yang } \\
\text { kecil imut-imut gini } e . .\end{array}$ & \\
\hline 5. & $\begin{array}{l}\text { PJ: Kakak cantek masok Kak diliat-liat dulu! } \\
\text { PB: Tas gini ada Kak ? } \\
\text { PJ: Ada untuk kakak cantek apa yang gak } \\
\text { ada yang penting masok dulu kak ee... }\end{array}$ & Strategi Perayuan \\
\hline 6. & $\begin{array}{l}\text { PB: Coba liat baju tu Kak! } \\
\text { PJ: Boleh sayang, sini masok cobak pakek } \\
\text { cantek kali ni satu lagi tinggal pas kali } \\
\text { dibadan adek tukan ambel tros kakak } \\
\text { kasi murah aja. }\end{array}$ & Strategi Perayuan \\
\hline 7. & $\begin{array}{l}\text { PJ: Sayang anak, sayang anak, sayang anak! } \\
\text { PB: Ada mobil yang maennya pakek rel tu } \\
\text { Dek? } \\
\text { PJ: Ada Kak ni yang paling bagus kami kasi } \\
\text { Kak, tinggal satu lagi ni Kak kami kasi } \\
\text { murah aja untuk kakak lah abesin barang } \\
\text { aja nanti gak ada lagi ni kak ambel tros } \\
\text { kak bagus pun ni! }\end{array}$ & Strategi Perayuan \\
\hline 8. & $\begin{array}{l}\text { PJ: Carik apa sayang sini dulu carik apa adek } \\
\text { tempat kakak ada ni apa adek carik? } \\
\text { PB: Berapa kaen ni Kak? } \\
\text { PJ: } 150 \text { aja untuk adek, kalok gak berapa } \\
\text { adek maunya? Untuk adek kakak kasi } \\
\text { murah aja ni. Satu aja kaennya dek } \\
\text { ambel dua kakak kasi murah lagi } \\
\text { sayang! }\end{array}$ & Strategi Perayuan \\
\hline 9. & $\begin{array}{l}\text { PJ: Buk di sini murah ni Buk ambel tros tiga } \\
15 \text { ribu aja bu sini! } \\
\text { PB: } 10 \text { ribu aja ya! Jurnal llmiah } \\
\text { PJ: Gak dapat ibuk oyy udahliah } 12 \text { ribuaja, } \\
\text { ya tapi jangan bilang-bilang orang untuk } \\
\quad \text { ibu aja tu ee... }\end{array}$ & Strategi Perayuan \\
\hline 10. & $\begin{array}{l}\text { PJ: Adek mameh sini lah singgah tempat } \\
\text { abang dulu carik apa adek? } \\
\text { PB: Berapa ni Bang? } \\
\text { PJ: Lima puluh aja untuk adek untuk apa } \\
\quad \text { mahal-mahal kali! }\end{array}$ & Strategi Perayuan \\
\hline 11. & $\begin{array}{l}\text { PB: Gapu ranup Kak saboh! } \\
\text { PJ: Dua ribe saboh! }\end{array}$ & Strategi Penghindaran \\
\hline
\end{tabular}




\begin{tabular}{|c|c|c|}
\hline 12. & $\begin{array}{l}\text { PJ: Tiga lima ribu, tiga lima ribu, tiga lima } \\
\text { ribu dipilih dipilih! } \\
\text { PB: Centongnya pak coba liat! } \\
\text { PJ: Tiga lima ribu, tiga lima ribu, tiga lima } \\
\text { ribu dipilih dipilih! }\end{array}$ & Strategi Penghindaran \\
\hline 13. & $\begin{array}{l}\text { PJ: } 20 \text { aja Kak, } 20 \text { aja Buk ambel tros } 20 \text { aja } \\
\text { PB: Ini gak kurang lagi? } \\
\text { PJ: Harga pas } 20 \text { aja, } 20 \text { aja }\end{array}$ & Strategi Penghindaran \\
\hline 14. & $\begin{array}{l}\text { PB: Kue ini satu Pak! } \\
\text { PJ: } 18 \text { udah ya, udah naek harganya mau? }\end{array}$ & Strategi Penghindaran \\
\hline 15 . & $\begin{array}{l}\text { PB: Dek na barang? (Dik, ada barang?) } \\
\text { PJ: na! (ada) }\end{array}$ & Strategi Keengganan \\
\hline 16. & $\begin{array}{l}\text { PB: Lem wajan satu Bang! } \\
\text { PJ: Oke! }\end{array}$ & Strategi Keengganan \\
\hline 17. & $\begin{array}{l}\text { PB: Ada minyak ganda pura toh? } \\
\text { PJ: Abes! }\end{array}$ & Strategi Keengganan \\
\hline 18. & $\begin{array}{l}\text { PJ: Cari apa Pak? } \\
\text { PB: Ada bingkisan rencong tak? }\end{array}$ & Strategi Penghormatan \\
\hline 19. & $\begin{array}{l}\text { PJ: Cari ukuran apa ibu biar kami cariin? } \\
\text { PB: XL jumbo ada? }\end{array}$ & Strategi Penghormatan \\
\hline 20. & $\begin{array}{l}\text { PB: Bang, kuda laot satu! } \\
\text { PJ: Oke Buk, satunya } 500 \text { ribu! } \\
\text { PB: Kuranglah Bang! } \\
\text { PJ: Gak bisa Buk susah udah dapetnya ni } \\
\quad \text { udah jarang orang carik lagi! }\end{array}$ & Strategi Penghargaan \\
\hline 21. & $\begin{array}{l}\text { PB: Berapa bayem dua iket Mak? } \\
\text { PJ: Lima ribu Dek oy... } \\
\text { PB: Tiga ribu aja gak bisa? } \\
\text { PJ: Gak bisa Dek, modal aja gak cukop tu! }\end{array}$ & Strategi Penghargaan \\
\hline
\end{tabular}




\section{Karakteristik Strategi Tindak Tutur}

Terdapat lima karakteristik strategi tindak tutur yang ditemukan dalam transaksi jual beli pedagang kaki lima pasar pagi Kota Sabang. Kalimat strategi tersebut dijelaskan sebagai berikut.

\section{Strategi Perayuan}

Strategi perayuan merupakan tindakan merayu yang dilakukan seseorang pada lawan tuturnya dengan cara yang diupayakan manis sedemikian rupa dengan maksud untuk lawan tuturnya terhanyut oleh katakata yang ia ucapkan sehingga lawan tutur tersebut merasa senang dan berkehendak sesuai dengan kehendak mitra tuturnya (Abdullah, 2014; Aladdin, 2012). Karakteristik strategi perayuan dapat dilihat pada data berikut.

1) PB: Aer mawar satu, Kak! PJ: Satu aja Dek oy? Ambel dua kakak kasi kurang lagi, ambel tros dua e!

Konteks: Tuturan pada data (1) tersebut merupakan interaksi yang terjadi antara penjual dan pembeli. Dalam tuturan tersebut saat pembeli meminta air mawar hanya satu saja, pedagang langsung merayu pembeli dengan kata "kakak kasi kurang |lagi, ambel teros dua e" dan langsung memasukkan barang tersebut ke dalam plastik. Penjual menyuruh dan memaksa pembeli untuk mengambil barang dagangannya lebih dari satu dengan menjanjikan bahwa harga barang yang pembeli ambil lebih murah harganya kalau si pembeli ambil barang tersebut lebih dari satu.
Percakapan tersebut jelas menunjukkan strategi perayuan yang dipakai penjual untuk merayu pembeli agar membeli barang dagangannya.

2) PJ: Mamper Dek, mamper Buk, masoklah sini dulu, dilihat dulu sini sini masok aja dulu yok, murah murah baju ni kakak kasih untuk adek aja!

PB: Berapaan yang ini ?

PJ: Murah aja untuk adek gak mahal-mahal kakak kasi 120 aja biasa kakak jual sama orang 130 !

Tuturan pada data (2) tersebut merupakan interaksi antara penjual dan pembeli. Dalam tuturan tersebut penjual menarik tangan pembeli untuk masuk melihat dagangannya dengan menjanjikan harga yang murah khusus untuk si pembeli. Ketika si pembeli menanyakan harga barang yang ia maksud, penjual kembali merayu si pembeli dengan mengatakan "Murah aja untuk adek gak mahal-mahal kakak kasi 120 aja biasa kakak jual sama orang 130!". Dalam konteks ini si penjual merayu sipembeli dengan menjanjikan harga barang tersebut dijual lebih murah untuk si pembeli dibandingkan dengan pembeli yang lain. Dalam konteks ini penjual jelas memakai strategi perayuan untuk memikat dengan menjanjikan harga khusus untuk si pembeli.

3) PJ: Cantek kali gelangnya ni lah kalok adek pakek!

PB: Berapa Kak?

PJ: 45 aja sayangku, coba dulu aja pasti cantek kali ditangan adek, karna orangnya putih pasti idop kali dia kalok dipakek. 
Konteks: Tuturan pada data (3) merupakan interaksi antara penjual dan pembeli. Dalam tuturan tersebut ketika pembeli sedang melihat-lihat gelang dan meminta gelang yang ia sukai untuk di ambilkan penjual langsung merayu pembeli dengan mengatakan "Cantek kali gelangnya $n i$ lah kalok adek pakek!" lalu pembeli bertanya berapa harga gelang tersebut dan penjual langsung menjawab dengan merayu pembeli tersebut sekali lagi dengan kata "45 aja sayangku, coba dulu aja pasti cantek kali ditangan adek, karna orangnya putih pasti idop kali dia kalo dipakek". Percakapan tersebut jelas menggunakan strategi perayuan di mana penjual merayu si pembeli dengan memuji kecantikan si pembeli.

\section{Strategi Penghindaran}

Penghindaran merupakan tindakan dalam wujud upaya untuk menghindari sesuatu yang tidak diinginkan, mengelak, menyingkir, agar terlepas atau menjauh dari apa yang dimaksud oleh lawan tutur (Rusjayanti, 2015; Sumarsono \& Partana, 2002). Karakteristik strategi penghindaran dapat dilihat pada data berikut.

4) PB: Gapu ranup Kak saboh (sirih satu Kak)

PJ: Dua ribe saboh! (dua buah seribu)

Tuturan pada data (4) tersebut merupakan interaksi antara penjual dan pembeli. Ketika pembeli meminta barang yang ia maksud penjual langsung men-jawab dengan harga barang tersebut seakan tidak mau barang tersebut untuk di tawar harganya, dapat dilihat dengan kata "Dua ribe saboh!". Jelas percakapan tersebut menggunakan strategi penghindaran di mana si penjual menghindar agar si pembeli tidak menawar harga barang tersebut sehingga ia langsung menyebutkan harga barang tersebut dan tidak dapat ditawar lagi.

5) PJ: Tiga lima ribu, tiga lima ribu, tiga lima ribu dipilih!

PB: Centongnya pak coba liat! PJ: Tiga lima ribu, tiga lima ribu, tiga lima ribu dipilih!

Tuturan pada data (5) tersebut merupakan interaksi antara

penjual dan pembeli. Saat penjual menjajakan barang dagangannya sambil berkata "Tiga lima ribu, tiga lima ribu, tiga lima ribu dipilih dipilih!" dengan nada suara yang keras datang pembeli dan meminta barang yang ia maksud untuk dilihat kemudian penjual memberi barang tersebut kepada pembeli dan langsung mengulang kata yang sebelumnya ia lontarkan kembali "Tiga lima ribu, tiga lima ribu, tiga lima ribu dipilih-dipilih!”. Terlihat jelas bahwa strategi yang digunakan dalam percakapan tersebut yaitu strategi penghindaran di mana si penjual tidak melayani si pembeli denganah baik karena takut untuk di tawar harga barang dagangannya. Ketika barang tersebut diminta oleh si pembeli kemudian langsung si penjual memberikannya namun ia langsung mengulangi kalimat yang sebelumnya ia katakan.

6) PJ: 20 aja Kak, 20 aja Buk ambel tros 20 aja PB: Ini gak kurang lagi? 
PJ: Harga pas 20 aja, 20 aja

Tuturan pada data (6) tersebut merupakan interaksi antara penjual dan pembeli. Ketika penjual menjajakan barang dagangannya dengan nada suara yang keras datang si pembeli untuk menawar barang yang ia maksud, langsung saja si pembeli melontarkan kata "Harga pas 20 aja, 20 aja".

Terlihat jelas percakapan tersebut menggunakan strategi penghindaran di mana si penjual menghindari tawaran yang si pembeli tanyakan kepadanya dengan mengulang kalimat yang sama dengan kalimat yang sebelumnya si penjual katakan.

\section{Strategi Keengganan}

Enggan berarti tidak mau melakukan sesuatu atas dasar apa pun, tidak suka terhadap suatu yang sedang dihadapi (Lestari \& Indiatmoko, 2016; Pramuniati \& Eviyanti, 2012). Karakteristik strategi keengganan dapat dilihat pada data berikut.

7) PB: Dek na barang? (Dik, ada barang?)

PJ: Na! (Ada!)

Tuturan pada data (7) tersebut merupakan interaksi antara penjual dan pembeli. Ketika si pembeli menanyakan barang yang dimaksud kepada penjual, penjual langsung menjawab dengan kata "na!" tanpa melakukan sesuatu. Terlihat jelas percakapan tersebut menggunakan strategi keengganan dimana si penjual hanya menjawab "na" (bahasa aceh) tanpa melakukan sesuatu. Si penjual akan melakukan tindakan jika lawan tuturnya tersebut menyuruh untuk melakukan sesuatu.
8) PB: Lem wajan satu Bang! PJ: Oke!

Tuturan pada data (8) tersebut merupakan interaksi antara penjual dan pembeli. Ketika pembeli meminta barang yang akan ia beli dengan kata "Lem wajan satu Bang!". Si penjual hanya merespons dengan menjawab kata "oke", seakan enggan melakukan sesuatu atau merespons dengan harga untuk sebuah lem wajan tersebut.

Terlihat jelas di mana percakapan tersebut menggunakan strategi keengganan di mana si penjual tidak menanyakan apap un kepada si pembeli atau merespons dengan hal yang lain terhadap si pembeli.

9) PB: Ada minyak ganda pura toh?

PJ: Abes!

Tuturan pada data (9) tersebut merupakan interaksi antara penjual dan pembeli. Saat pembeli bertanya tentang barang yang ia maksud, penjual langsung menjawab dengan kata "abes!" tanpa melontarkan kata yang lain. Terlihat jelas strategi yang digunakan dalam percakap-an ini yaitu strategi keengganan di mana si penjual hanya merespons dengan kata "abes!" tanpa mencari barang tersebut terlebih dahulu dan menanyakan sesuatu hal yang diinginkan lain oleh si pembeli.

\section{Strategi Penghormatan}

Penghormatan merupakan proses atau perbuatan menghormati (Kemdikbud, 2020; Nakrowi \& Pujiyanti, 2019). Menghormati terkait dengan masalah posisi status sosial antara penutur dan mitra tutur, penghormatan biasa dilakukan kepada 
mitra tutur yang status sosialnya lebih tinggi dari penutur.

10) PJ: Cari apa Pak?

PB: Ada bingkisan rencong tak?

Konteks: Tuturan pada data (10) tersebut merupakan interaksi antara penjual dan pembeli. Penjual menanyakan dengan nada suara yang lemah lembut kepada pembeli yang melihat-lihat dagangannya dengan menanyakan "Cari apa Pak?”. Dengan pertanyaan yang ia lontarkan tersebut kepada lawan tuturnya dapat dilihat bahwa ia menghormati status sosial antara penutur dan lawan tuturnya karena terkait usia yang cukup jauh. Jelas percakapan tersebut menggunakan strategi peng-hormatan di mana si penjual yang usianya lebih muda dari si pembeli memanggil dengan sebutan pak untuk menghormati lawan tutur yang jauh lebih tua dari usia si penjual.

11) PJ: Cari ukuran apa ibu biar kami cariin?

PB: XL jumbo ada ?

Tuturan pada data (11) tersebut merupakan interaksi antara penjual dan pembeli. Di mana penjual menanyakan kepada pembeli "Cari ukuran apa ibu biar kami cariin?" ia bertanya dengan nada pelan kepada lawan tuturnya karna penjual melihat dengan siapa ia sedang berbicara maka dari itu penjual menanyakan dengan nada yang pelan dan memanggil kami untuk dirinya agar terlihat sopan saat berbicara dengan lawan tuturnya. Terlihat jelas strategi yang digunakan dalam percakapan tersebut yaitu strategi penghormatan di mana si penjual memanggil sebutan ibu untuk lawan tuturnya karna merasa lawan tuturnya tersebut memiliki usia yang jauh lebih tua dari mitra tutur, dengan memanggil lawan tuturnya dengan sebutan ibu lawan

tuturnya tersebut merasa lebih dihormati.

\section{Strategi Penghargaan}

Menghargai lebih menekankan pada unsur makna, atau bobot yang patut dihargai (Camalia, 2016). Strategi ini lebih melihat atau menghargai suatu barang yang di anggap bernilai lebih dari barangbarang biasanya. Berbeda dengan menghormati yang lebih menekankan pada unsur makna status sosial dengan lawan tuturnya, strategi ini juga dipakai dalam transaksi jual beli.

12) PB: Bang, kuda laot satu! PJ: Oke Buk, satunya 500 ribu! PB: Kuranglah Bang!

PJ: Gak bisa Buk susah udah dapetnya ni udah jarang orang carik lagi!

Tuturan pada data (12) merupakan interaksi antara penjual dan pembeli. Pada saat pembeli meminta agar harga barang yang pembeli minta untuk diturunkan penjual menjawab "Gak bisa Buk susah udah dapetnya ni udah jarang orang carik lagi!" yang mana pada kata tersebut penjual tidak dapat memberikan harga sesuai dengan yang pembeli minta karna barang yang dijualnya tersebut sudah jarang ditemukan dan tidak banyak lagi orang yang bekerja. Strategi yang digunakan dalam percakapan tersebut menggunakan strategi penghargaan di mana si penjual enggan mengurangi harga barang yang ia jual karena barang 
tersebut sulit untuk didapatkan. Mengapa dikatakan strategi penghargaan karna si penjual menghargai bahwa barang tersebut sulit untuk didapatkan maka dari itu ia menjual barang tersebut dengan harga yang mahal.

13) PB: Berapa bayem dua iket Mak?

PJ: Lima ribu Dek oy...

PB: Tiga ribu aja gk bisa?

PJ: Gak bisa Dek, modal aja gak cukop tu!

Tuturan pada data (13) merupakan interaksi antara penjual dan pembeli. Saat pembeli meminta agar harga barang yang ia maksud untuk di tawar penjual menjawab "Gak bisa Dek, modal aja gak cukop tu!". Kata tersebut jelas diucapkan oleh penjual agar pembeli lebih menghargai harga yang telah ditentukan oleh si penjual. Jelas percakapan tersebut menggunakan strategi penghargaan di mana harga bayam yang ditawarkan oleh si pembeli tidak bisa untuk mengembalikan modal si penjual, maka dari itu si penjual tidak dapat memberikan harga yang di tetapkan oleh si penjual karna ia menghargai bahwa barang yang ia jual belikan berharga dan semua orang memerlukan barang tersebut. Indonesia daAladdin,, A. 2012. Analisis

\section{PENUTUP}

\section{Simpulan}

Hasil penelitian ini menunjukkan adanya karakteristik strategi yang digunakan oleh pedagang dalam interaksi jual beli yang berbeda-beda, di antaranya ada dua strategi penghormatan, tiga strategi keengganan, empat strategi penghindaran, sepuluh strategi perayuan, dan dua strategi penghargaan di mana kelima strategi tersebut dipakai dalam transaksi jual beli yang ada pada pedagang kaki lima Pasar Pagi Kota Sabang. Semua strategi tersebut dipakai dalam berinteraksi dengan pembeli dan bahasa yang dimiliki pedagang juga merupakan ciri khas tersendiri untuk menarik melanggan, mereka memakai kosa kata yang sangat singkat, tidak formal dan dimengerti oleh orang yang mendengarkannya.

\section{Saran}

Perlu penelitian lanjutan untuk menyempurnakan hasil penelitian mengenai karakteristik ragam bahasa pedagang kaki lima. Hal ini disebabkan waktu dan tempat pelaksanaan penelitian ini sangat terbatas. Oleh karena itu, disarankan kepada peneliti lainnya untuk menyempurnakan hasil penelitian ini.

\section{DAFTAR PUSTAKA}

Abdullah, M. A. R. 2014. Strategi komunikasi lisan bahasa Jepun dalam kalangan pelajar Melayu di Malaysia. Universiti Putra Malaysia.

Penggunaan Strategi Komunikasi Dalam Komunikasi Lisan Bahasa Arab. GEMA Online Journal of Language Studies, 12(2), 645-666. Camalia, M. 2016. Strategi Kesantunan Pada Tuturan Penjual Daging Ayam di Pasar Tradisional Sidoharjo Lamongan. Diponegoro University. 
Fajrik, M., Sofyan, A., \& Setyari, A. D. 2018. Istilah-Istilah Komponen Perahu dan Struktur Pengurus Nelayan di Desa Kilensari Kecamatan Panarukan Kabupaten Situbondo (Kajian Etimologi dan Semantik). PUBLIKASI BUDAYA, 6(2), 152-158.

Kemdikbud. 2020. Kamus Besar Bahasa Indonesia. Diakses pada April 19, 2020, from https://kbbi.kemdikbud.go.id/

Kusumawati, D. 2014. Karakteristik Penggunaan Bahasa Pada Transaksi Jual Beli di Toko Online. Tesis Universitas Sebelas Maret Surakarta.

Lestari, T. P., \& Indiatmoko, B. 2016. Pelanggaran Prinsip Percakapan Dan Parameter Pragmatik Dalam Wacana Stand Up Comedy Dodit Mulyanto. Seloka: Jurnal Pendidikan Bahasa Dan Sastra Indonesia, 5(2), 148-162.

Mulyana, D. 2015. Ilmu Komunikasi: Suatu Pengantar. Bandung: Remaja Rosdakarya.

Mulyati, Y., Pramukti, E., Supratmi, N., Setiawati, L., \& Supriyana, A. 2019. Bahasa Indonesia. Jakarta: Universitas Terbuka.

Muzdalifah, S., Sukidin, \& Suharso, P. 2019. Karakteristik Pedagang Tradisional di Pasar Kepatihan Kabupaten Jember. JURNAL PENDIDIKAN EKONOMI: Jurnal Ilmiah Ilmu Pendidikan, Ilmu Ekonomi Dan Ilmu Sosial, 13(1), 94-100.

Nakrowi, Z. S., \& Pujiyanti, A. 2019. Strategi Kesantunan Berbahasa Suku Jawa dalam Interaksi Antarsuku di Halmahera Utara.
RETORIKA: Jurnal Bahasa, Sastra, Dan Pengajarannya, 12(1), 105-116.

Narbuko, C., \& Achmadi, A. 2002. Metodelogi Penelitian. Jakarta: Bumi Aksara.

Nasrullah, R., Suganda, D., Wagiati, \& Riyanto, S. 2019. Komunikasi Terapeutik dalam Pemulihan Kompetensi Linguistik Pasien Penyandang Afasia Broca. LITERASI: Jurnal Ilmiah Pendidikan Bahasa, Sastra Indonesia Dan Daerah, 9(2), 7990.

Pramuniati, I., \& Eviyanti, E. 2012. Strategi Tindak Tutur Dan Kepekaan Pragmatik Melarang Pada Penutur Bahasa Aceh Dialek Aceh Utara. Laporan Hasil Penelitian Fundamental: Universitas Negeri Medan.

Priastuti, E. 2010. Karakteristik Pemakaian Bahasa dalam Iklan Komersial di Radio. Universitas Sebelas Maret.

Putrayasa, I. G. N. K. 2018. Ragam Bahasa. Bali: Universitas Udayana.

Rohim, S. 2009. Teori komuniksai: Perpektif, Ragam dan Aplikasi. Jakarta: Rineka Cipta.

Rusjayanti, $_{\text {,tra }}$ A. 2015. Analisis terjemahan kalimat yang merepresentasikan tuturan penolakan dan rangkaiannya (refusal set) pada novel ,the deception point? dan dampaknya terhadap kualitas terjemahan (Sebuah Pendekatan Pragmatik). UNS (Sebelas Maret University).

Sakdiah, Cahyani, M., \& Nuthihar, R. 2019. Fungsi Tindak Tutur Direktif 
Pedagang Asongan pada Kapal

Motor Penyeberangan di

Pelabuhan Ulee Lheue Banda Aceh. VOCATECH: Vocational Education and Technology Journal, 1(1), 43-46.

Sumarsono, \& Partana, P. 2002. Sosiolinguistik. Yogyakarta: Sabda dan Pustaka Pelajar.

Yahya, I. K. 2013. Tindak Tutur Direktif dalam Interaksi Belaja Mengajar Mata Pelajaran Bahasa dan Satra Indonesia di SMA Negeri 1 Mlati Sleman Yogyakarta. Tesis Universitas Negeri Yogyakarta. 